\title{
Counterfactual Impact Evaluation of the Project Internships for Young Job Seekers
}

\begin{abstract}
The growing youth unemployment across Europe raises the need to take appropriate measures. One of steps taken towards decreasing it by the European Union has been the program Youth Guarantee, implemented by a number of member states. Despite the relatively lower youth unemployment, the Czech Republic has implemented this program as well, and supported the realization of the project Internships for Young Job Seekers, whose aim was to ease the transition for students from schools to the labour market thanks to internships in companies. The effects which internship related project bring for their participants have been evaluated in other EU countries, mainly in Germany, but also in Sweden or France. However, evidence about internship' effectiveness has been missing for the Czech Republic, and this paper fills this existing knowledge gap with the use of counterfactual impact evaluation methods. In the paper, we have focused on examining the impacts of internships on personal income and economic status of trainees by using the propensity score matching, difference-in-differences estimation and two complementary methods - ordinary least squares and multinomial logit. The results confirmed a positive impact of internships on treated project participants regarding both outcome variables, and thus, are consistent with the majority of literature in the field.
\end{abstract}

KEYWORDS: counterfactual impact evaluation, internships, youth unemployment, matching, difference-in-differences

RECEIVED 12 March 2016; ACCEPTED 17 October 2016.

\section{INTRODUCTION}

The high rates of unemployment across Europe brought the attention of policy makers towards the labour market and made the need to increase the employment a priority. Each year more than $10 \%$ of the EU budget is spent through the European Social Fund on measures aiming at increasing the employment and employability, as well as the number of vacancies. Consequently, a variety of programs has been implemented across the EU. One of the adopted measures is training in companies, namely internships, which are the key focus of this paper. However, the evidence about their effectiveness is relatively scarce.

In this paper, we consider the counterfactual impact evaluation (CIE) to be sufficient evidence due to the fact that it shows causal effects of implemented measures on treated individuals. Internship related programs have been evaluated mostly in Germany. There is also some evidence from France, Denmark and Sweden but in other European countries, even though similar programs have been realized, the evidence about their effects is still missing. Moreover, the evidence on the effects of training in companies is available mostly for unemployed and in a small measure for employed.

Most of the studies find positive effects of trainings in companies on the employment rate of participants when compared to a control group, whose members were not treated (i.e., Wolff and Jozwiak, 2007 or Kopf, 2009). Besides the employment rate, our research also focuses on the effect on personal income, which has been found to be increasing after an unemployed individual passes an internship (Rinne, Schneider and Uhlendorff, 2011). However, several studies showed that the beneficial effects of internships start to show only in the medium and long run, as for instance, in the research by Fitzenberger, Osikominu, Völter (2006) or Lechner, Miquel and Wunsch (2011), who evaluated the effects after as much as 8 years.

The youth unemployment has been even a more severe problem in the EU than the overall unemployment. For example, in Spain, the rate exceeded 50\% in 2013, while in the Czech Republic it approached 20\% in the same year. Within this age group, the unemployment occurs right after students' transition from schools to the labour market. Thus, the prevention of unemployment

1 Vědunka Kopečná: Institute of Economic Studies, Faculty of Social Sciences, Charles University. Email: vedunka.kopecna@fsv.cuni.cz 
embodied in internships seems to be a convenient solution. However, the evidence of their effects for the youth is missing. Our research aims at filling this information gap covering the case of the Czech Republic, where the project called Internships for Young Job Seekers was conducted. The CIE focused on estimating the effects of internships on economic status and personal income of trainees was carried out 1.5 years after the project participants registered into the project, in order to provide them with some time to apply their acquired skills on the real labour market.

This study is unique not only in the examined target group but also in the scope of the used methods. All the reviewed academic papers used the propensity score matching (PSM) as the sole method for estimating impacts of treatments. Besides the PSM with the nearest-neighbour matching algorithm, we enriched our evaluation of internship effects on economic status and personal income of treated subjects also with difference-in-differences estimation (DiD), as well as with logit modelling and ordinary least squares estimation to increase the reliability of our results.

The rest of this paper is organized as follows. Section 2 focuses on the phenomenon of training within companies in the literature and provides an overview about similar measures implemented in other EU countries, mainly in Germany. The subsequent section introduces the project, as well as the structure of internships and participants. Section 4 focuses on data and methodologies used throughout CIE. Section 5 then presents detailed results and finally, Section 6 concludes.

\section{LITERATURE REVIEW}

If we focus solely on the issue of within company training, which is central to this paper, we come to a conclusion that there exist only a very limited number of published articles, and most of them concern themselves with projects realized in Germany, if not indicated otherwise. Moreover, all reviewed articles use only the PSM as the evaluation method.

Our paper is unique not only in the scope of methods but also in the target group, since majority of relevant articles examine the unemployed. Wolff and Jozwiak (2007) and also Kopf (2013) proved that trainings in companies contributed to a higher probability of their employment. However, Wolff and Jozwiak (2007) carried out the evaluation separately also for different age groups and found that internships were less effective for the unemployed youth who were younger than 25 years.

Besides the employment rate, trainings within companies appear to have a positive impact on earnings as well, as shown by Rinne, Schneider and Uhlendorff (2011) and for the case of Denmark also by Jespersen et al. (2008). The latter author went further and compared the effects of within company trainings with classroom trainings, where indisputably better results brought trainings in real companies.

We decided to evaluate the performance of the treated individuals after 1.5 year following their registration into the project, based on a hypothesis that trainees need some time to apply their acquired skills and knowledge on the labour market. This proved to be true according to a research by Fitzenberger, Osikominu, Völter (2006) and Fitzenberger and Völter (2007). The conclusions of the two studies showed that in the short run, effects of internships were either inconclusive or negative, while in the medium and long run, the employment rate of trainees increased significantly when compared to a control group. Lechner, Miquel and Wunsch (2007) went one step further and evaluated the effects 4 years after the start of the program, and in a subsequent research (2011), after 8 years. Even after such a long period of time, the performance of former trainees was undoubtedly better with 10-20 pp higher employment rates as compared to a control group. The trio of authors also evaluated short run effects with negative results which contribute to confirming our hypothesis that trainees need some time to benefit from internships on the real labour market.

Despite generally favourable impacts of trainings in companies, there has also been some evidence on negative effects as described by Wünsch and Lechner (2008). 2.5 years after the start of the program, the trainees stayed unemployed for a much longer period of time than individuals included in a control group, which was a result contrasting with all the others.

Sianesi (2002) and (2008) enriched her evaluation for the Swedish case with a range of other programs besides within company trainings. However, when results were mutually compared, the more the measure was similar to a real job, the better the treated individual performed later-on in the real labour market.

The only exception regarding the target group was in Chéron et al. (2010) for the case of France, who evaluated the probability of becoming unemployed for the case of employees who passed training. Once again, results were favourable for the treated subjects. Moreover, authors confirmed that trainings had a beneficial effect not only on the employment rate but also on wages, which increased by $7 \mathrm{pp}$ more within the treated group than within the control group. 
However, similar evidence on the effectiveness of trainings in companies for the Czech Republic has been missing. Moreover, since the Czech government committed to a goal of decreasing youth unemployment by adopting a package called Youth Guarantee implemented also by most of the other EU members, our study focuses on the particular case of internships realized by youth, and thus fills the existing knowledge gap.

\section{PROJECT DESCRIPTION}

The project Internships for Young Job Seekers 2 (shortly Internships for Youth 2) immediately followed the previous similar project and was created within the framework of the Youth Guarantee program implemented by most EU members. The program goal has been to decrease the youth unemployment currently on the rise since its potentially harmful effects bring a macro-social cost with increased criminality and worsening health of the long-term unemployed (O'Higgins, 2015).

The two projects were conducted consecutively from September 2012 up until November 2015 by the Fund of Further Education, funded organization established by the Ministry of Labour and Social Affairs of the Czech Republic. The primary objective was to help graduates to transfer from schools to the labour market by completing internships in firms. The target group were students in their final year of studies in high schools, higher vocational schools and universities.

Over the course of the two projects, more than 17200 people registered via a specially designed information system, and a total of 3869 internships were realized, from which 939 during the first project and 2930 during its continuation Internships for Youth 2. The interest in the project participation was subject to seasonal influences. Students, with regard to their time constraints, preferred to participate especially during summer holidays. Based on the questionnaires which the trainees filled over the course of their internships, the most common motivation for trainees to participate in the project was to acquire practical skills in the fields they studied, the opportunity to learn new things from experienced professionals and related improvements of their CVs. A very low probability of obtaining other working experience outside of the project indicated by $63 \%$ of trainees motivated them to participate as well.

Half of the internships were provided by self-employed individuals, and then, mostly by small private companies employing up to five employees. This structure is not surprising since larger companies often have their own internship programs. The typical answer to the question about providers' motivation for participating concerned the non-binding possibility to test a potential employee, social responsibility and overall project usefulness for the youth.

The procedure of selecting trainees started with the providers creating and advertising a so-called Internship card with information about the offered internship as, such as its field, duration, job position, start date and location. Candidates were then able to browse Internship cards and apply to those which interested them. A restriction was placed on submissions of applications where candidates could apply only to internships whose field complied with their study field. After a week, an internship card that advertised the possibility to apply was closed, and all submitted applications meeting the field criteria were sent to the internship provider. After that, the selection procedure was analogous to any other hiring process. The provider checked applicants' CVs and invited selected ones for a personal interview. Then he chose one candidate and the selection process was completed.

Overall, 3087 internship selection processes were successful. However, in 151 cases, an internship agreement between the provider and a selected candidate was not signed due to unknown reasons. 2936 agreements were signed and internships started. Only in 6 cases, a trainee did not attend his internship.

71 internships were terminated prematurely based on on-the-spot controls, and another 11 based on administrative controls. Therefore, $2.7 \%$ of internships were not successfully completed.

\section{Internships' structure}

Internships had been starting continuously on the $1^{\text {st }}$ and $15^{\text {th }}$ day each month during the project duration with the highest number during summer holidays. Last internships started in August 2015. The Figure 1 shows their fields. Economics and business administration largely prevailed with $45 \%$ followed by trade, marketing and advertising, and the third place with $11 \%$ occupied construction. 
Fig.1: Internship fields

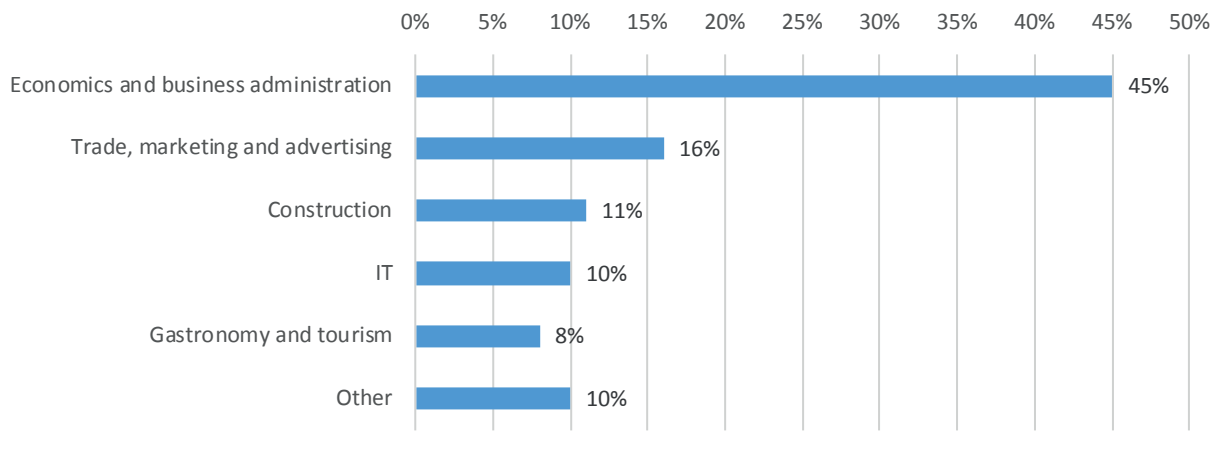

Regarding job positions, $36 \%$ of the trainees worked as administrative assistants, $6 \%$ as marketing specialists, $5 \%$ as architects and $4 \%$ as accountants. Rest of job positions were occupied by less than $3 \%$ of trainees.

Internships were realized across whole of the Czech Republic, but the Moravian regions prevailed largely - mostly MoraviaSilesia, South Moravia and Zlín region. Also, a number of internships were realized in the region of Prague. The selection of Moravian regions is based on the high number of university students and higher unemployment rates. Regarding Prague, many students from other cities arrive to study there, so there is a higher concentration of students in Prague, and also a large number of companies are located there. Figure 2 shows the regional distribution of internships.

Fig. 2: Regional distribution of internships

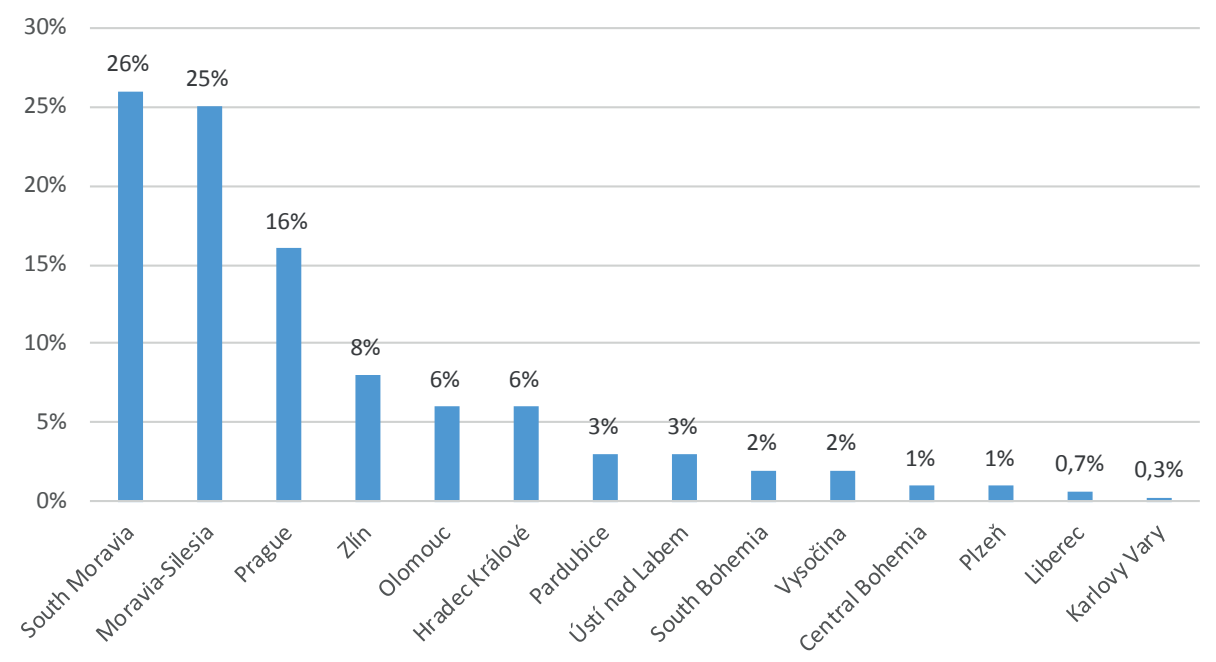

The duration of $92 \%$ of internships was 300 working hours. Internships could last from 2 to 4 months but in $53 \%$ they lasted for 3 months. 26\% lasted for 2 months and 20\% for 4 months. Only 1\% lasted one month. Related literature in the field concerns itself with a so-called 'lock-in' effect, where participants are in fact locked out of the real labour market because of the treatment. Since all participants of our project were students at that time, the 'lock-in' effect was of minimal importance, contrary to the case if the target group were the unemployed. 


\section{TG and CG descriptive statistics}

The treated group (TG) was designed as former trainees 1.5 years after registering into the project. At the time of evaluation, this time criteria met 939 trainees participating in the first project Internships for Youth. The control group (CG) comprised students who applied for some internship but never became trainees either during the first or the subsequent project. 1131 registered students met this criterion. Both groups were contacted with a request to provide information and data for CIE 18 months after their registration into the project information system. 167 people from the intervention group and 400 people from the control group did not provide any data and thus, the final number of persons whose data were used for CIE was 772 in TG and 731 in CG.

Figures 3 to 6 show the comparison of the group structures regarding age, gender, region of permanent residence and highest education. Despite the fact that both groups are very similar, which is one of the assumption for the use of CIE methods, the problem of differential attrition is present. The lack of interest of CG members to participate in the survey presumably originated in the fact that did not benefit from internships in any way, and thus, did not feel the need to answer the evaluation questions. Two focus groups with 30 CG members were carried out to find out about their motivation or why they did not become trainees. Among reasons of not realizing any internship, they mentioned stays abroad or finding a regular job outside of the project, which suggests that the CG members might not have become trainees intentionally and not because of their failure. Still, the underlying reasons why the attrition rates differ are in fact unknown and might bias the results of CIE, which is an undeniable limitation of the analysis and results must be interpreted with regard to this drawback.

Fig. 3: Gender structure

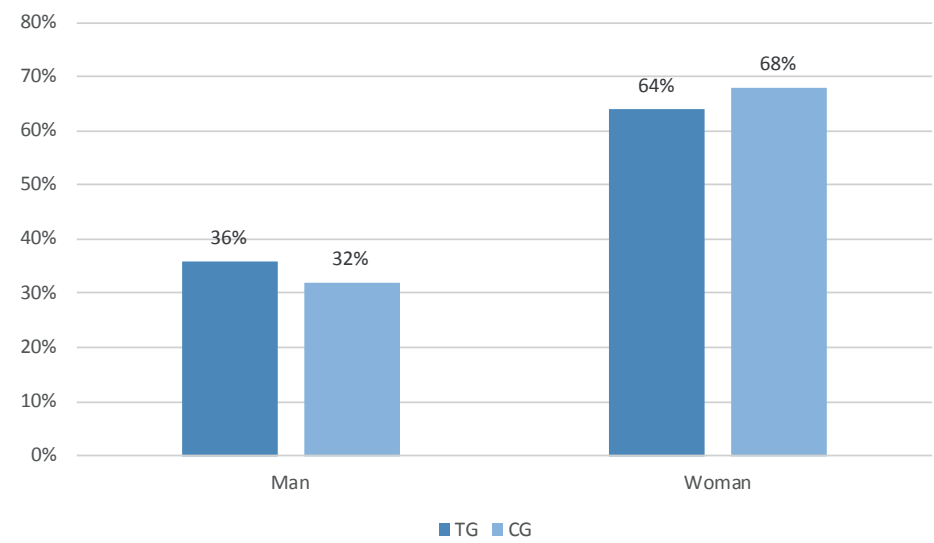

Fig. 4: Age structure

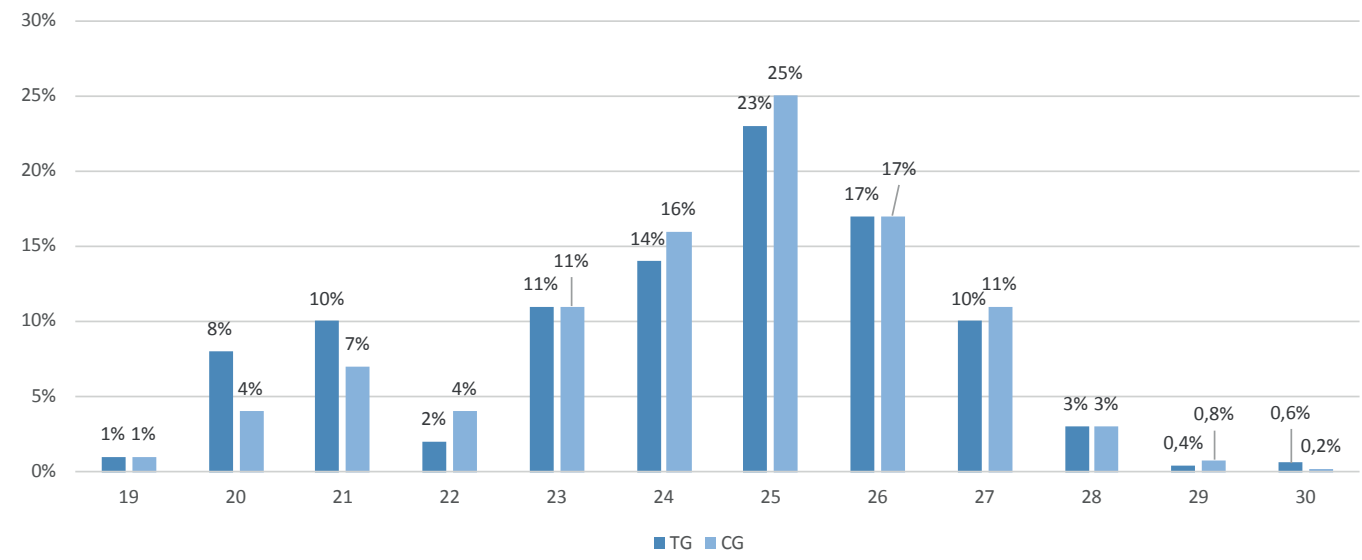


Fig. 5: Region of permanent residence

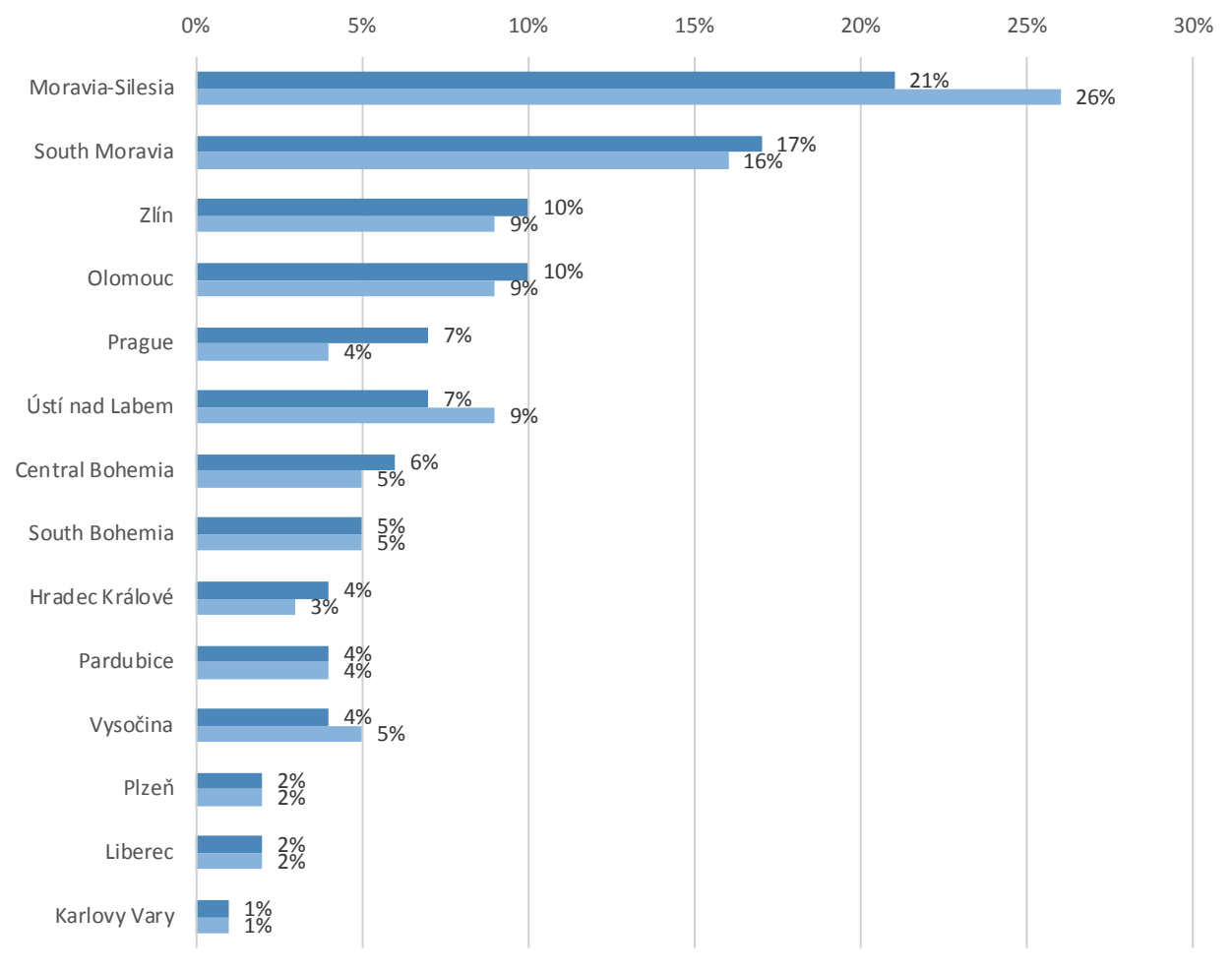

$\square \mathrm{TG} \backsim \mathrm{CG}$

Fig. 6: Highest education structure

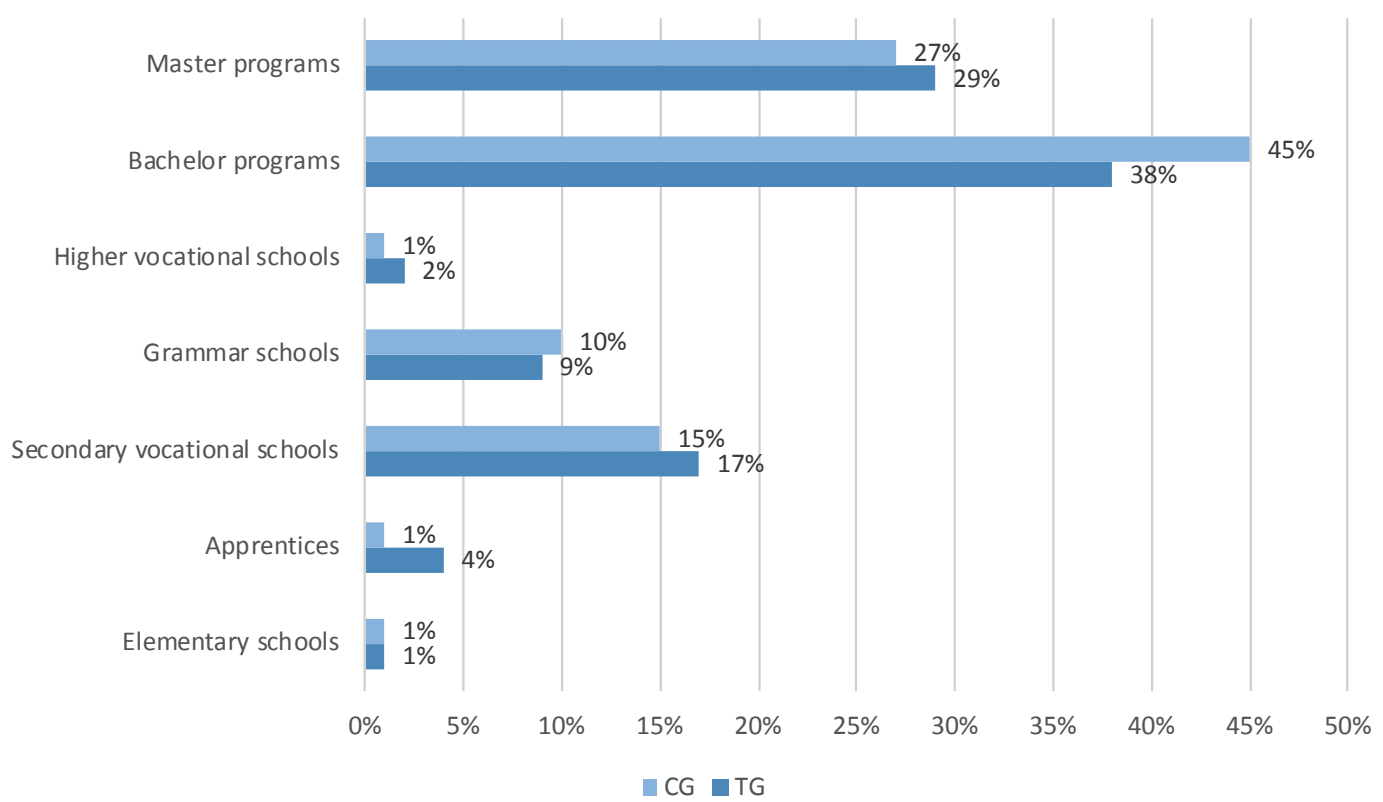


Women prevailed with a share of roughly two thirds. Most of TG and CG members resided in the Moravian regions predominantly Moravian-Silesian and South Moravian - where high rates of unemployment are a long-term issue. Moreover, several universities are in these regions, and thus there is a wider range of potential internship candidates. University graduates consisted up to $68 \%$ of TG and $72 \%$ of CG where bachelor program graduates prevailed. $17 \%$ of TG and $15 \%$ of CG attended secondary vocational school, and 9\% of TG and 10\% of CG grammar schools. Rest were either apprentices (4\% of TG, 1\% of CG) or graduated from higher vocational schools ( $2 \%$ of TG, $1 \%$ of CG). $1 \%$ in both groups graduated only from elementary schools and the possible explanation of their presence in the data set is the fact that these few people stated that they had dropped out of a secondary school, thus their highest education remained primary.

$60 \%$ of participants in both groups pursued economically and business administration oriented study programs. A much smaller portion studied programs related to trade, marketing and advertisement (17\% of TG and 24\% of CG). The top trio of most prominent fields is closed by IT ( $11 \%$ of TG and $8 \%$ of CG).

\section{DATA AND METHODOLOGY}

Demographic details about trainees and their internships, as well as information about the chosen CG were taken from the internal project database run by the Fund of further education. It included information about the project participants' age, gender, highest education, region of permanent residence, number of internship applications sent, driving license ownership and language skills. Regarding the internships, data about their length, start and end dates, fields, job positions, hours worked and region where they took place were available.

Specifically designed questionnaires for internship providers and trainees represented a second source of data. They were required to be filled at the beginning and towards the end of each internship and comprised various questions on motivation, expectations, contentment with the internship itself and self-assessment of acquired theoretical knowledge and practical and soft skills. The questionnaires were collected using the computer-assisted web interviewing method.

Key part of the data for CIE originated from a survey collected by the computer-assisted telephone interviewing method where TG and CG were interviewed. As mentioned, 772 former trainees and 731 participants, without any internship and constituting CG, agreed to answer the survey questions. Probably due to the fact that all of them were familiar with the project and interviewers were very experienced and did not skip any questions we did not have any missing data.

Questions in the survey targeted current and past economic situations of respondents, their job searching process, studies and other relevant inquiries. Moreover, the questions were customized for different economic groups - employees, students, selfemployed, unemployed and economically inactive (i.e., mothers on parental leave).

The main goal of CIE was to examine whether internships had any effects on economic status and personal income of trainees, thus we measured the change in these two variables from the time of the registration into the project to 1.5 years after that. A prerequisite of the use of CIE methods is that the two examined groups - TG and CG - are similar enough in their key characteristics which we have shown in Section 3. CG provides us with information about what would have happen with the treated individuals if the intervention had not been experienced by them. For addressing this question, both difference-in-differences estimation and the PSM were applied, as well as the multinomial logit model and OLS for estimating the impact on the economic status and personal income respectively.

Before proceeding to describing CIE methods, it is useful to define the examined outcome variables - the personal income and the economic status of individuals.

\section{Personal income}

Respondents were asked to quote their income in CZK per month both at the time of registration into the project $\left(\mathrm{t}_{0}\right)$ and 1.5 years after that $\left(\mathrm{t}_{1}\right)$. Table 1 compares TG with CG based on their income in $\mathrm{t}_{0}$ and $\mathrm{t}_{1} .72 \%$ of TG and $62 \%$ of CG did not have any income. After 1.5 years, the income of both groups shifted towards higher values, however, more persons in CG stayed incomeless. The most frequent income category within the TG was between 5000-10000 CZK/month. 
Tab. 1: Income categories of TG and CG

\begin{tabular}{lllll}
\hline Income categories & TG in $\mathrm{t}_{\mathrm{o}}$ & $\mathrm{CG}$ in $\mathrm{t}_{\mathrm{o}}$ & TG in $\mathrm{t}_{1}$ & $\mathrm{CG}_{\text {in }}$ \\
\hline Without income & $71 \%$ & $62 \%$ & $21 \%$ & $25 \%$ \\
\hline$<5000$ & $17 \%$ & $21 \%$ & $16 \%$ & $19 \%$ \\
\hline $5000-10000$ & $10 \%$ & $14 \%$ & $25 \%$ & $22 \%$ \\
\hline $10001-15000$ & $1 \%$ & $2 \%$ & $16 \%$ & $16 \%$ \\
\hline $15001-20000$ & $0.5 \%$ & $1 \%$ & $13 \%$ & $13 \%$ \\
\hline $20001-25000$ & $0 \%$ & $0.4 \%$ & $5 \%$ & $3 \%$ \\
\hline $250001-30000$ & $0.5 \%$ & $0 \%$ & $2 \%$ & $1 \%$ \\
\hline$>30000$ & $0 \%$ & $0 \%$ & $2 \%$ & $1 \%$ \\
\hline
\end{tabular}

Table 2 compares both groups in terms of the income change. Positive change is more frequent in TG while negative change is more frequent in CG.

Tab. 2: Change of income of TG and CG

\begin{tabular}{lll}
\hline Income changes intervals & TG & CG \\
\hline$-25000--20001$ & $0 \%$ & $0.1 \%$ \\
\hline$-20000--15001$ & $0.1 \%$ & $0 \%$ \\
\hline$-15000--10001$ & $0.3 \%$ & $1 \%$ \\
\hline$-10000--5001$ & $2 \%$ & $2 \%$ \\
\hline$-5000--1$ & $3 \%$ & $6 \%$ \\
\hline $0-5000$ & $43 \%$ & $47 \%$ \\
\hline $5001-10000$ & $19 \%$ & $17 \%$ \\
\hline $10001-15000$ & $15 \%$ & $15 \%$ \\
\hline $15001-20000$ & $11 \%$ & $8 \%$ \\
\hline $20001-25000$ & $4 \%$ & $2 \%$ \\
\hline $25001-30000$ & $1 \%$ & $0.4 \%$ \\
\hline$>30000$ & $1 \%$ & $1 \%$ \\
\hline
\end{tabular}

Lastly, we take a look at the development of the average personal income of both groups including the counterfactual line representing the potential development of TG if its members had not been treated, that is had not passed an internship. According to the depicted lines in the Figure 7, the average income of TG grew more, which is to be either confirmed or rejected by CIE methods described below. 
Fig. 7: Average income development

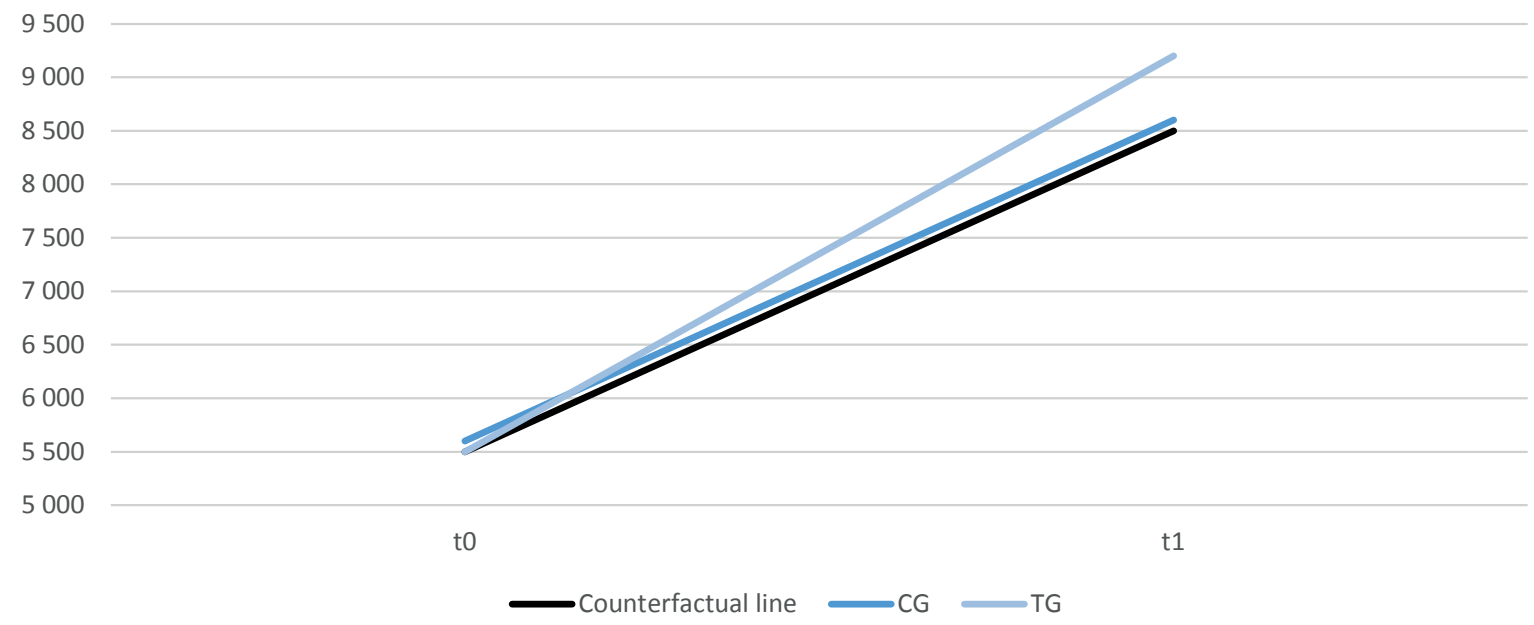

\section{Economic status}

Six different categories of the economic status were defined - employee, self-employed, student, working student, unemployed and economically inactive. At $\mathrm{t}_{0}$, all the participants were students in their final year of studies. Part of them besides studying also worked. Then, after 1.5 years, the economic status of participants could take on any form of the six categories.

The change is assessed as positive (coded by ' 1 '), negative (coded by ' 1 ') or neutral (coded by ' 0 '). The following five types of changes are perceived as the positives:

- $\quad$ student $\rightarrow$ employee/self-employed/working student

- $\quad$ working student $\rightarrow$ employee/self-employed (under the condition that the person still studies his initial study program)

The condition imposed on working students is set due to the fact that when a working student graduates or unsuccessfully terminates his study, he automatically becomes a worker and the amount of available information prevents us from assessing whether the economic status in this case actually improved or not. For this reason, we decided to evaluate this change as neutral. Moreover, since this methodology is applied for both groups it does not bias the results because we examine the intergroup difference.

As a negative, the following five types of change are perceived:

- $\quad$ student $\rightarrow$ unemployed/economically inactive

- $\quad$ working student $\rightarrow$ unemployed/economically inactive/student

All the other options are considered to be neutral, for example, remaining a working student or remaining a student. Also, neutral is the change from a working student to an employee/self-employed if the individual did terminate his initial study program due to reasons mentioned above.

According to Figure 8 , we can observe that $72 \%$ of TG has been only studying at the time when they registered into the project compared to $62 \%$ of CG.

Figure 9 shows the frequency of each economic status of participants after 1.5 years. The ratio of employees is higher by $7 \mathrm{pp}$ in the TG. Interestingly, according to the survey, up to $80 \%$ of employees in TG and 79\% in CG were working full-time, $14 \%$ in TG and $13 \%$ in CG were working based on an agreement on work and only $5 \%$ of employees in TG and $8 \%$ in CG had a part-time job, which is in line with the trend in the Czech Republic where working part-time has not been very popular among employers. However, this proportion of employment types was rather different within the group of working students for logical reason that in general they are not able to sacrifice all their time to working. Thus, $80 \%$ of them in TG and $78 \%$ in CG were working based on an agreement on work, $10 \%$ in TG and $14 \%$ in CG were working part-time and only $4 \%$ in TG and $5 \%$ in CG full-time. Another 
Fig. 8: Economic status of TG and CG in $\mathrm{t}_{\mathrm{o}}$

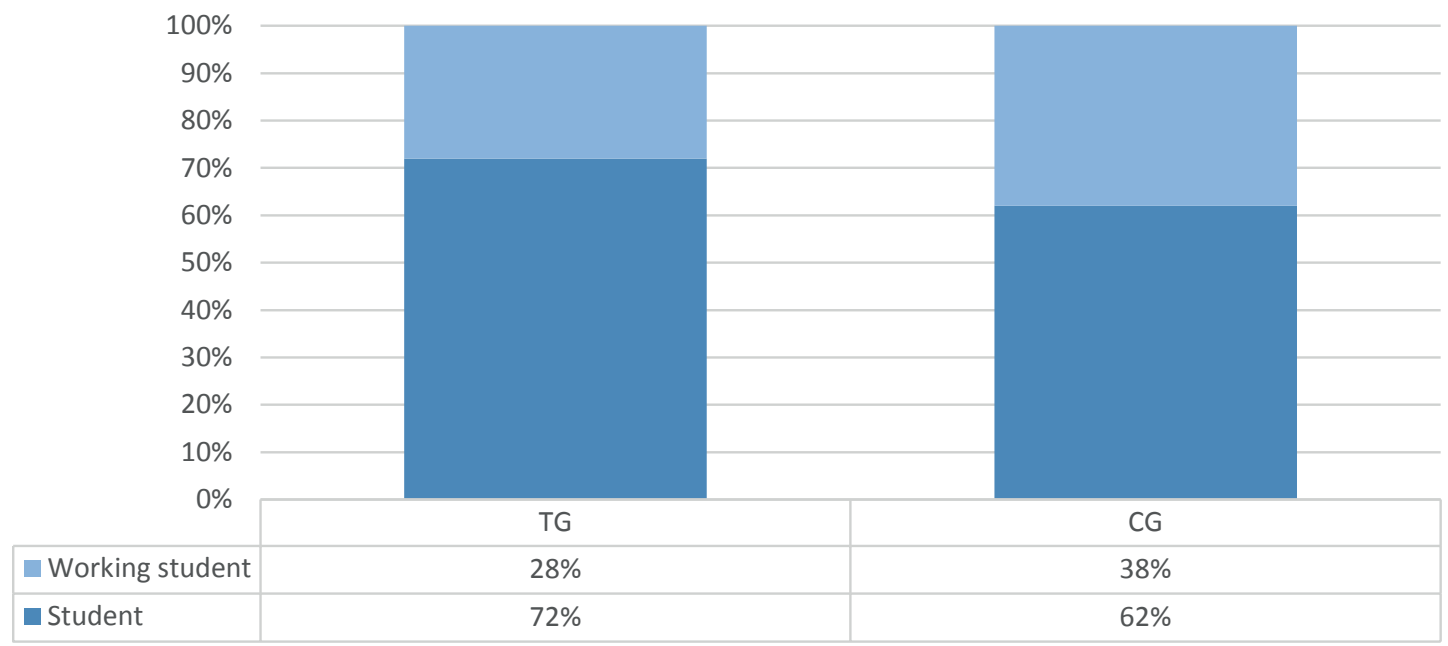

Fig. 9: Economic status of $T G$ and $C G$ in $t_{1}$

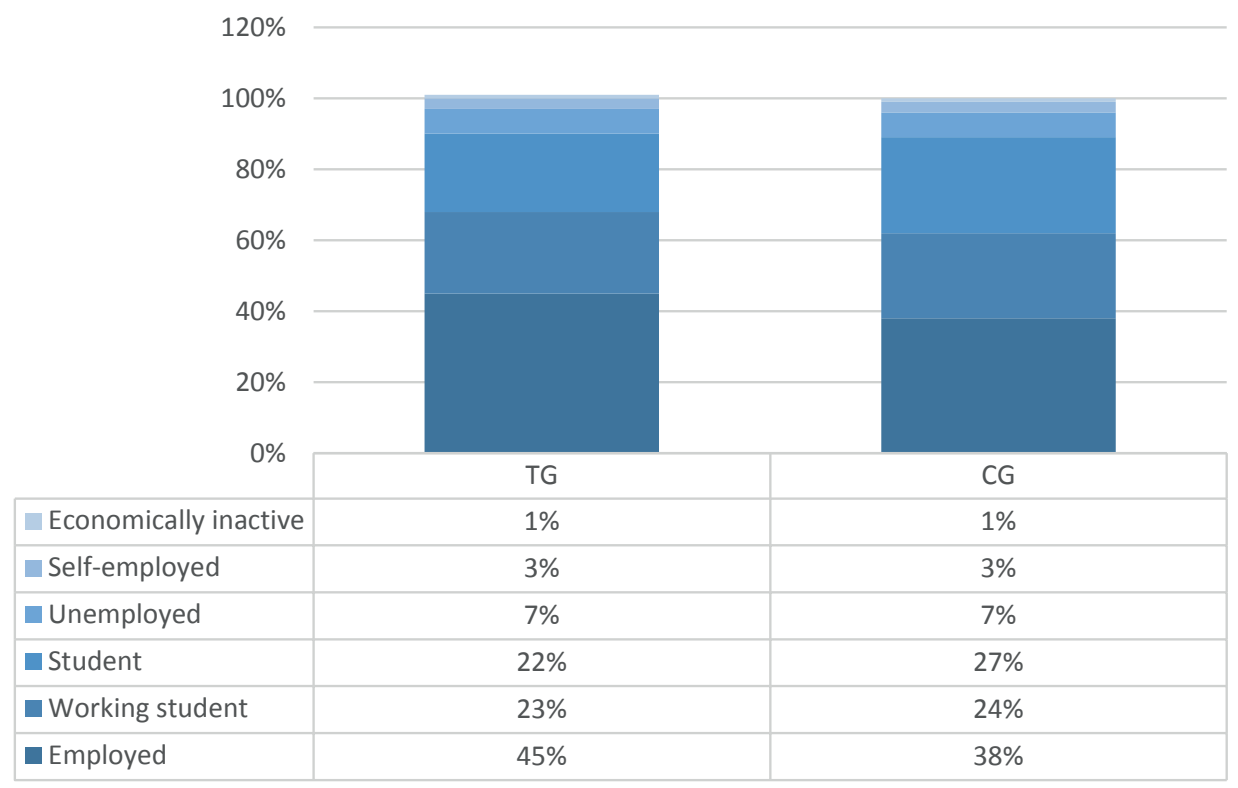

recent trend slowly rampant in the Czech labour market has been fixed-term employment contracts. Nearly two thirds of employees in both groups have signed such a kind of contract.

According to answers provided by the unemployed, over $75 \%$ of them in both groups had been looking for a job actively and the rest claimed they had already found one and would start it in the near future. Most of the unemployed seeking employment considered their lack of working experience to be the biggest barrier to a successful job search. Among other reasons, highly competitive labour market and an overall poor economic situation in the region were mentioned. On the contrary, most unemployed refused to seek the cause of their situation in the internship inefficiency. An insufficient level of English appeared as a potential reason as well.

All of the former trainees, currently economically inactive, were woman on a maternal/parental leave. $75 \%$ of them stated that they had been looking for a job and the rest claimed to have already found one. The same applied for CG with the exception of two persons who had received a disability pension. 
If we now examine the change in the economic status over the 1.5 years, we arrive to a result that the frequency of positive change is 9 pp higher in TG and conversely, the frequency of negative change is by 5 pp higher in CG.

Tab. 3: Change in economic status

\begin{tabular}{lll}
\hline & TG & CG \\
\hline Negative change & $97(12 \%)$ & $125(17 \%)$ \\
\hline No change & $284(37 \%)$ & $298(41 \%)$ \\
\hline Positive change & $391(51 \%)$ & $308(42 \%)$ \\
\hline Total & $772(100 \%)$ & $731(100 \%)$ \\
\hline
\end{tabular}

For a more detailed and conclusive verification of internship effects on economic status and personal income we employ PSM, DiD and OLS estimation, as well as multinomial logit modelling.

\section{Propensity score matching}

The PSM has become one of the most used evaluation methods. The principle is that each person in TG is paired with one or more persons from the CG, whose members did not experience any treatment, based on some observable variables. The first step is to measure how similar persons are expressed in terms of a probability - the propensity score - of being treated based on a list of observable variables not related to the treatment (i.e., demographic characteristics). In our case the propensity score was calculated based on age, gender, region of permanent residence, level of highest education, status of initial studies from $t_{0}$ (i.e., still studying, graduated, unsuccessfully terminated), level of highest education of respondent's mother, voluntarily studying in one's free time, participating in any other labour market related project, field of studies and initial economic status in $\mathrm{t}_{0}$. The full list of used variables together with an explanation of each of them is available in the appendix. In order to verify that later in the analysis we use only comparable and relevant subjects from CG, we examine the similarity of probability density distributions of propensity scores of the two groups. Then we match persons based on the similarity of their propensity scores using the nearest-neighbour matching algorithm. The principle of this estimation algorithm is the minimization of difference between propensity scores of a matched pair - former trainee and CG member. A potential disadvantage of this algorithm is a decreased efficiency due to many neglected near neighbours. We use the variant with replacement of control units which brings improved quality of matching but on the other hand also a higher variance (Caliendo et al., 2015).

After matching, it is important to assess the quality of it based on an obtained balance, for example, if the similarity of characteristics of the two matched groups is statistically significant (Becker and Ichino, 2002). We examined the difference between the means of matching variables in the two groups using a paired $t$-test and looked for statistically insignificant differences on a $5 \%$ confidence level. Subsequently, we proceeded to compute the average treatment effect on the treated (ATET), which was found as a difference of outcomes of the two matched groups (i.e., difference in personal incomes). Lastly, we ran a $t$-test to find whether the estimated effect is statistically significant.

\section{Difference-in-Differences estimation}

The usage of this method was conditional on data availability where information about both TG and CG must be available from both times before and after a treatment. The DiD estimate was computed comparing the difference of the two groups' outcomes (e.g., personal income) at $\mathrm{t}_{0}$ and $\mathrm{t}_{1}$. This technique presumed that both groups had a common trend of dependent variable development, 
thus identical condition development and reaction on alternated conditions with the exception of the exogenous treatment indicating variable are assumed. In our case, the common growth trend was partly induced by the fact that both groups were young graduates and all of them had been students at $t_{0}$ and after that they started to search for jobs and became employed. Therefore, their income inevitably rose.

The next assumption was a strict intervention impact only on TG which could be considered as valid in the internship case, since the scenario of trainees sharing all their acquired skills and knowledge with CG seemed rather improbable. The last DiD assumption concerned the expectation of intervention impacts to show already during the examined time period (Manning, 2008). The time for contacting former trainees was set to around one year after their internship, mainly due to this assumption so that they had time to properly apply acquired knowledge and skills.

Three types of DiD estimators were considered - pooled OLS, fixed effects (FE) and random effects (RE). In order to choose the most suitable one, we conducted a series of three statistical tests - F-test of panel effects presence, Breusch-Pagan Lagrange Multiplier test for RE and Hausman's test (Woolridge, 2010).

The panel data model, where the dependent variable is the personal income, created based on available variables used for the evaluation is in the following form:

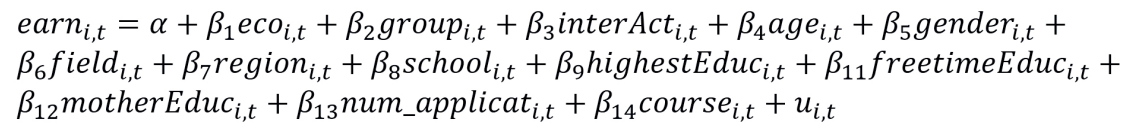

The most important is the parameter. The variable interAct is a product of binary variables time and group thus becomes equal to one when an individual is a former trainee 1,5 year after the registration into the project. Otherwise it is equal to zero. Thus, reflects the internship impact.

\section{Cross-sectional analysis}

Two other methods were chosen as complementary for confirming the results - a multinomial logistic regression for evaluating the effect on economic status and a linear regression to estimate the impact on personal income which we cannot use for the case of economic status, since its change is a discrete categorical variable with three different values $(-1,0,1)$. Both methods require crosssectional data, thus the dataset was transformed accordingly.

\section{Multinomial Logit model}

The logistic regression is a fairly standard method of the mathematical statistics. It is used for estimating the probability of an event occurrence based on known facts influencing it. The goal is to find a model explaining relations between dependent and exogenous variables (Aldrich and Nelson, 1984). The use of logit is conditional on a discrete dependent variable which in our case was the change in individual's economic status. As described, this variable can take on three different categories - positive (coded by ' 1 '), negative ('-1') and neutral (' 0 '). Moreover, since $y$ is multicategorial, we had to employ the multinomial logit version, which is a generalization of the binomial logit (Pecáková, 2007). The estimation outcome provided us with the information whether the internships contributed to a better economic status of an individual.

The model is specified as follows:

eco_change $_{i}=\alpha+\beta_{1}$ ecot $_{i}+\beta_{2}$ group $_{i}+\beta_{3}$ age $_{i}+\beta_{4}$ gender $_{i}+\beta_{5}$ field $_{i}+$ $\beta_{6}$ region $+\beta_{7}$ school $_{i}+\beta_{8}$ highestEduc $_{i}+\beta_{9}$ freetimeEduc $_{i}+\beta_{10}$ motherEduc $_{i}+$ $\beta_{11}$ num_applicat $_{i}+\beta_{12}$ course $_{i, t}+u_{i}$ 
We are interested in the parameter indicating the internship impact on the change of economic status. The results are interpreted with respect to the neutral change chosen as a reference category for the dependent variable. The reference category for the variable is 0 , for example, the control group. The outcome of the estimation are two coefficients called log odds - one for the negative vs. neutral and one for the positive vs. neutral change in economic status. This means that when the estimate is less (greater) than zero, the probability of a given type of change is lower (higher) for TG and vice versa.

\section{Linear regression}

The last method applied within CIE framework was standard general linear regression estimation. Since the most frequent problem in cross-sectional data is the residual heteroskedasticity, which causes the estimator to be inefficient and induced conclusions to be invalid we need to test for it. In case the estimated model contains heteroskedasticity or violates the Gauss-Markov assumption in any other way, we need to take appropriate measures. In such a case, we can use the generalized regression estimator which is the best linear unbiased and effective estimator and deals with the heteroskedasticity (Woolridge, 2009).

We set the model in the form given by the equation (3).

earn_change $_{i}=\alpha+\beta_{1}$ eco $_{i}+\beta_{2}$ group $_{i}+\beta_{3}$ age $_{i}+\beta_{4}$ gender $_{i}+\beta_{5}$ field $_{i}+$ $\beta_{6}$ region $_{i}+\beta_{7}$ school $_{i}+\beta_{8}$ highestEduc $_{i}+\beta_{9}$ freetimeEduc $_{i}+\beta_{10}$ motherEduc $_{i}+$ $\beta_{11}$ num_applicat $_{i}+\beta_{12}$ course $_{i, t}+u_{i}$

The dependent variable is calculated as a difference between the current and former personal income and once again the attention is focused on the parameter since its value indicates the contribution of being a trainee to the change in personal income.

\section{RESULTS}

\section{Effect of internships on personal income}

When examining the results obtained based on the used CIE methods, we first focused on the personal income change. This characteristic was chosen partly due to the fact that it is easily measurable but mainly because a higher income positively correlates with higher living standard and indicates a better position of an individual on the labour market.

The first applied method was PSM, where we started with estimating the propensity score of individuals in both groups based on matching variables described in the methodology section. The Figure 10 shows the comparison of probability distributions of estimated propensity scores between the two groups. As shown in the Figure 10, the distributions were very similar and therefore, we proceeded to match former trainees with CG members based on the nearest-neighbour matching algorithm.

Before proceeding to compute the ATET, we checked the matching balance reached in matching variables, which indicated how successful the process of creating CG similar enough to TG was. We chose to perform a 1000 repetitions bootstrap to achieve better accuracy and then, computed Kolmogorov-Smirnov test statistics. Kolmogorov-Smirnov test tests the similarity between CG and TG regarding their statistical distribution of model variables (Abadie, 2002). The null hypothesis states that the two observations come from the same distribution. We ran the test for all the matching variables and came to a conclusion that the null hypothesis was not rejected in any case. Thus, the similarity of the profile of the two groups was satisfactory and allowed us to draw conclusions about the internship impact on the personal income.

According to the results summarized in the Table 4, we saw that the personal income rose on an average by 1843 CZK more within TG than CG with a $99 \%$ statistical significance. Since the $95 \%$ confidence interval stretched over positive values only, from 930.49 up to $2756.13 \mathrm{CZK}$, we could conclude that the estimated internship impact on the personal income was positive and statistically significant. 
Fig. 10: Propensity score probability distributions

Propensity score distribution of TG

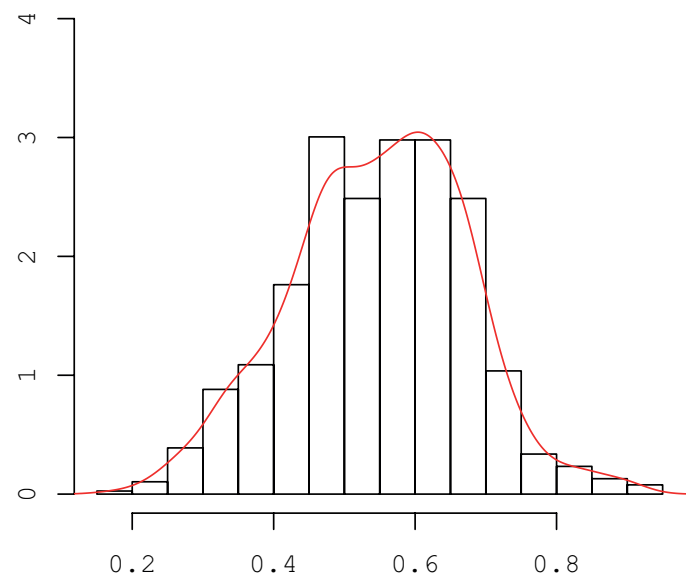

Propensity score distribution of CG

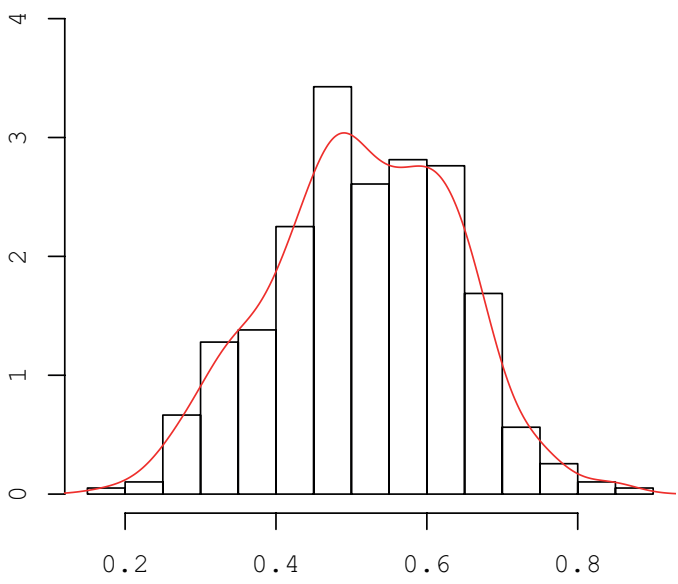

Next, we applied the $\mathrm{DiD}$ estimation. Since it was not clear from the beginning which estimator - pooled OLS, FE or RE - was the most suitable one, we had to estimate all the three and tested the results. Table 5 shows the parameter, identified in the methodology sections as key for distinguishing the internship impact, estimated by the three estimators together with their standard error and $p$-value.

In order to choose the correct model specification, we performed three statistical test - Hausman test, Breusch-Pagan Lagrange Multiplier test for RE and F-test. Table 2 shows the test results according to which the best choice was RE model.

After choosing the best estimator, we verified that the model defined by the equation (1) did not violate any of the Gauss-Markov assumptions. The $F$-test indicated that the model was correctly specified. Another important issue was the serial correlation which we checked using the Breusch-Godfrey serial correlation test setting $\mathrm{H} 0$ as the absence of serial correlation, which we expected to be rejected since the serial correlation poses a complication more in time series than in panel data. It really was the case on a $99 \%$ probability level. However, according to the Breusch-Pagan test, the heteroskedasticity was present, thus the estimated parameter was not efficient. In order to deal with the heteroskedasticity, we estimated the covariates consistent with it by using the White method and obtained a lower standard error which helped in narrowing down the confidence interval. The Table 7 summarizes the test results.

The key parameter was estimated as $1761.831 \mathrm{CZK} /$ month with a standard error 312.3018 . Thus, we got the $99 \%$ confidence interval as. Since it did not contain negative numbers, we could state that the treatment in the form on internships had a positive impact on the personal income of trainees and raised it in average by $1762 \mathrm{CZK}$ a month. This finding was in line with the estimated ATET.

To further improve the robustness of the results, we transformed the dataset into a cross-sectional form and estimated the model given by the equation (3) by the least squares estimation. The outcome is listed in Table 8.

Analogically to the previous case, we tested the model specification and again found heteroskedastic residuals as shown in Table 9. In order to obtain linear, unbiased and efficient estimates we employed the generalized least squares (GLS) estimation.

The parameter estimated by generalized least squares reached the value $1305.60 \mathrm{CZK} / \mathrm{month}$ with the standard error 403.74 and $p$-value 0.00125 . Therefore, the GLS estimation results suggested that the internship impact on the personal income change was positive and statistically significant. The 99\% confidence interval stretched from 514.2696 CZK to 2096.93 CZK. This result was again in line with the DiD estimation and PSM results, even though this method provided us with the lowest estimated impact on the income. 
Tab. 4: ATET - personal income change

\begin{tabular}{ll}
\hline Estimation outcome & Value \\
\hline Estimated ATET & 1843.3 \\
\hline Standard error & 465.73 \\
\hline t-statistics & 3.958 \\
\hline $95 \%$ confidence interval & $<930.49 ; 2756.13>$ \\
\hline p-value & 7.5591 e-0 $* * *$ \\
\hline
\end{tabular}

Tab. 5: DiD estimation

\begin{tabular}{lllll}
\hline & Parameter & Standard error & t-test & p-value \\
\hline Pooled OLS & 1764.6514 & 327.5376 & 5.3876 & 7.701 e-08*** \\
\hline FE & 1778.74 & 323.71 & 5.495 & 4.587 e-08*** \\
\hline RE & 1761.8313 & 312.3018 & 5.6414 & 1.846 e-08*** \\
\hline
\end{tabular}

Tab.6: Model specification tests

\begin{tabular}{ll}
\hline & p-value \\
\hline F-test & 1.699 e-06 *** \\
\hline Ho: pooled OLS is an adequate specification & Ho was rejected in favour of $\mathrm{H}_{1}$. \\
\hline H1: fixed effects is an adequate specification & \\
\hline Breusch-Pagan Lagrange Multiplier test & 5.863 e-05 *** \\
\hline Ho: pooled OLS is an adequate specification & Ho was rejected in favour of $\mathrm{H}_{1}$. \\
\hline H1: random effects is an adequate specification & \\
\hline Hausman test & 0.1456 \\
\hline Ho: random effects is an adequate specification & Ho was not rejected. \\
\hline H1: fixed effects is an adequate specification & \\
\hline Best choice & Random effects \\
\hline
\end{tabular}

Tab. 7: Random effects model testing

\begin{tabular}{ll}
\hline Criterion & Random effects \\
\hline Adjusted R2 & 0.50088 \\
\hline F-test p-value & $2.22 \mathrm{e}-16 * * *$ \\
\hline Breush-Pagan test p-value: Ho - homoskedasticity & $2.2 \mathrm{e}-16 * * *$ \\
\hline Breusch-Godfrey test p-value: Ho - no serial correlation & $0.8148 * * *$ \\
\hline
\end{tabular}


Tab. 8: LS estimation

\begin{tabular}{lllll}
\hline & Parameter & Standard error & t-test & p-value \\
\hline LS estimator & 1305.60 & 403.74 & 3.235 & $0.001249^{* *}$ \\
\hline
\end{tabular}

Tab. 9: LS model testing

\begin{tabular}{ll}
\hline Criterion & value \\
\hline Adjusted R2 & 0.1619 \\
\hline F-test p-value & $2.22 \mathrm{e}-16 * * *$ \\
\hline Breush-Pagan test p-value: Ho - homoskedasticity & $2.2 \mathrm{e}-16 * * *$ \\
\hline
\end{tabular}

\section{Effect of internships on economic status}

For evaluating the effects of internships on the economic status, once again we applied the PSM with exactly the same matching variables as in the case of personal income. Therefore, the estimated propensity scores of individuals and their distributions were identical. Since the reached matching balance was satisfactory, we could compute the ATET.

According to the results in the Table 10, we could conclude that on a 99\% confidence level, the trainees' economic status improved on an average more than that of the CG members, and thus confirmed positive impact of internships.

Tab. 10: Estimated ATET - economic status change

\begin{tabular}{ll}
\hline Estimation outcome & value \\
\hline Estimated ATET index & 0.1143 \\
\hline Standard error & 0.0359 \\
\hline t-statistics & 3.1823 \\
\hline $95 \%$ confidence interval & $<0.0439 ; 0.1847>$ \\
\hline p-value & 0.0015 \\
\hline
\end{tabular}

The multinomial logit was chosen as a complementary method to verify the result of the PSM since the outcome variable is discrete with three different values: $-1,0$ and 1 . We estimated the model given by the equation (2) and examined the estimate of parameter. As explained in the methodology section, based on the negative sign of the parameter in the case of negative economic status change and positive sign in the positive status change when it comes to the treated group, it appeared that on a $1 \%$ significance level former trainees have a lower probability of the economic status worsening compared to its no change and at the same time higher probability of economic status improvement also compared to its no change. This conclusion thus confirmed the result given by the PSM. 
Tab. 11: Multinomial logit estimation

\begin{tabular}{lllll}
\hline & $\begin{array}{l}\text { Estimated parameter } \\
(\text { ref }=0)\end{array}$ & Standard error & $95 \%$ confidence interval & $p$-value \\
\hline $\begin{array}{l}\text { Negative economic status } \\
\text { change }\end{array}$ & -0.2380 & 0.0558 & $<-0.2882 ;-0.1878>$ & $1.1102 \mathrm{e}^{-15 * * *}$ \\
\hline $\begin{array}{l}\text { Positive economic status } \\
\text { change }\end{array}$ & 0.1886 & 0.0297 & $<0.0944 ; 0.2828>$ & $7.1854 \mathrm{e}^{-04 * * *}$ \\
\hline
\end{tabular}

\section{CONCLUSION}

This paper presented a counterfactual impact evaluation of the project Internships for Youth and its continuation Internships for Youth 2. The project targeted young students in their last year of studies, who prepared themselves for the transition from schools to the labour market. The goal of the project was to ease this transition with the help of internships in companies and prevent the treated subjects from becoming unemployed and consequently contribute to decreasing the youth unemployment.

We estimated the treatment effects for internships realized between September 2012 and August 2014. Internships realized later could not be considered because the follow-up survey investigating the effects had to be carried out during the project duration due to financial and administrative reasons, and also in order to provide trainees with some time to benefit from their acquired skills on the real labour market. Internships were provided mainly by self-employed and small private companies employing up to five employees all over the Czech Republic. However, the highest number of internships occurred in Moravian regions - Moravia-Silesia, South Moravia and Zlín region. The field of most of the internships was economics and business administration followed by trade, marketing and also construction.

The primary data source used for the CIE stemmed from the follow-up survey conducted 1.5 years after TG and CG members registered into the project. We contacted both former trainees and persons who registered in the project and showed an interest to attend an internship but then never started due to multiple reasons. According to their statements, they either were not chosen by any internship provider or what was more frequent - they found a job outside of the project on the real labour market. Those people constituted the control group. For evaluating the impacts of internships, we used standard counterfactual impact evaluation methods - the propensity score matching and difference-in-differences estimation. Moreover, in order to increase the robustness and reliability of result as a complementary method for estimating the impact on the personal income, we applied the least squares regression and the change in economic status was assessed using the multinomial logit model. The scope of the used methods was rather large and in this sense unique in the literature because the majority of studies in the field used only matching methods.

The economic status was defined by six categories - employee, self-employed, student, working student, unemployed and economically inactive. Due to the specificity of the target group, all participants were either students or working students at the time of registration into the project. After 1.5 years, their status could have worsened, improved or stayed the same. The results of the propensity score matching showed that the economic status of former trainees improved on average more than the economic status of the control group members. Also, the logit estimation confirmed that being a trainee increased the probability of being either employed or self-employed. In case of personal income, we first applied the same PSM methodology as in the case of the economic status, and then conducted a diagnostics with the aim of choosing an appropriate DiD estimator. After identifying random effects as the most suitable one, we proceeded to assess the results. Both methods, PSM and DiD estimation revealed that thanks to internships, the trainees managed to get a higher income than they would have reached given they had not passed any internship. Moreover, the outcome of the least squares estimation also supported the reached conclusion regarding the positive effect of internships. However, the obtained results need to be interpreted with respect to the differential attrition which might have induced some bias due to certain unknown underlying and unobservable characteristics of TG and CG in which they might differ (i.e., motivation, willingness to be active on the labour market, etc.)

Our results are in general consistent with the literature in the field where most authors found positive effects of within company trainings on the employment rate of the target group of unemployed (e.g., Wolff and Jozwiak, 2007 or Kopf, 2009) and also on earnings (Rinne, Schneider and Uhlendorff, 2011). Thus, internships have proved themselves to be an effective tool not only for the unemployed but also for the youth acting as precautionary measure against their unemployment. 


\section{ACKNOWLEDGEMENT}

This article was supported by the Faculty of Social Sciences project SVV 260 233. The author would like to thank two anonymous reviewers for their valuable comments.

\section{REFERENCES}

Abadie, A. (2002). Bootstrap Tests for Distributional Treatment Effects in Instrumental Variable Models. Journal of the American Statistical Association. 97(457), p. 284-292.

Aldrich, J. H. and Nelson, F. D. (1984). Linear Probability, Logit, and Probit Models. $1^{\text {st }}$ edition. Beverly Hills: Sage Publications.

Becker, S. O. and Ichino, A. (2002). Estimation of average treatment effects based on propensity scores. The Stata Journal. 1(4), p. 358-377.

Cameron, A. C. and Trivedi, P. K. (2013). Microeconometrics: methods and applications. Cambridge: Cambridge University Press.

Chéron, A., Rouland, B., \& Wolff, F. C. (2010). Returns to firm-provided training in FR: Evidence on mobility and wages. $\mathrm{HAL}$.

Fitzenberger, B. and Völter, R. (2007). Long-run effects of training programs for the unemployed in DE (E). Labour Economics, 14(4), 730755 .

Fitzenberger, B., Osikominu, A. and Völter, R. (2006). Get training or wait?: long-run employment effects of training programs for the unemployed in $D E(W)($ No. 2006, 17). IAB discussion paper.

Jespersen, S. T., Munch, J. R. and Skipper, L. (2008). Costs and benefits of Danish active labour market programmes. Labour economics, 15(5), $859-884$.

Kopf, E. (2013). Short training for welfare recipients in DE: which types work?.International Journal of Manpower, 34(5), 486-516.

Lechner, M., Miquel, R. and Wunsch, C. (2007). The curse and blessing of training the unemployed in a changing economy: The case of DE (E) after unification. German Economic Review, 8(4), 468-509.

Lechner, M., Miquel, R. and Wunsch, C. (2011). Long-run effects of public sector sponsored training in DE (W). Journal of the European Economic Association, 9(4), 742-784.
Manning, A. (2008). Differences-in-Differences and A Brief Introduction to Panel Data. Lectures on London School of Economics.

O'Higgins, N. (2015). Youth Unemployment. IZA Policy Paper No. 103. Bonn: Institute for the Study of Labor.

Pecáková, I. (2007). Logistická regrese s vícekategoriální vysvětlovanou proměnnou. Acta Oeconomica Pragensia. 15(1), p. 86-g6.

Rinne, U., Schneider, M. and Uhlendorff, A. (2011). Do the skilled and prime-aged unemployed benefit more from training? Effect heterogeneity of public training programmes in DE. Applied Economics, 43(25), 3465-3494.

Sianesi, B. (2002). Swedish active labour market programmes in the 1990s: overall effectiveness and differential performance (No. Wo2/03). Institute for Fiscal Studies.

Sianesi, B. (2008). Differential effects of active labour market programs for the unemployed. Labour economics, 15(3), 370-399.

Wolff, J. and Jozwiak, E. (2007). Does short-term training activate meanstested unemployment benefit recipients in DE? (No. 2007, 29). IAB discussion paper.

Wooldridge, J. M. (2009). Introductory econometrics: a modern approach. $4^{\text {th }}$ edition. Mason, $\mathrm{OH}$ : Cengage Learning.

Wooldridge, J. M. (2010). Econometric analysis of cross section and panel data. $2^{\text {nd }}$ edition. Cambridge: MIT Press.

Wünsch, C. and Lechner, M. (2008). What did all the money do? On the general ineffectiveness of recent West German labour market programmes. Kyklos, 61(1),134-174. 


\section{APPENDIX}

\begin{tabular}{|c|c|c|}
\hline Variable & Description & Type \\
\hline age & Age & numerical \\
\hline course & Participation in any other employment promoting course or project & binary \\
\hline earn & Personal income & numerical \\
\hline earn_change & Personal income change & numerical \\
\hline eco & Economic status & categorical \\
\hline eco_to & Economic status at the time of the registration to the project & categorical \\
\hline eco_change & Economic status change & categorical \\
\hline school & Status of respondent's initial study & categorical \\
\hline freetimeEduc & Self-education in respondent's free time & binary \\
\hline gender & Gender & binary \\
\hline group & Treatment group membership & binary \\
\hline highestEduc & Highest education & categorical \\
\hline interAct & Product of variables group and time & binary \\
\hline motherEduc & Respondent's mother's highest education & categorical \\
\hline num_applicat & Number of internship applications sent by a respondent & binary \\
\hline field & Field of studies & categorical \\
\hline region & Region of permanent residence & categorical \\
\hline time & $\begin{array}{l}\text { Variable indicating either the time at the registration to the project }\left(t_{0}\right) \text { or the month } \\
\text { preceding the survey }\left(t_{1}\right)\end{array}$ & binary \\
\hline
\end{tabular}

